doi: $10.26529 /$ cepsj.271

\title{
Engaging Young Children with Mathematical Activities Involving Different Representations: Triangles, Patterns, and Counting Objects
}

Dina Tirosh ${ }^{1}$, Pessia TsamiR ${ }^{1}$, Ruthi Barkai ${ }^{2}$ And Esther Levenson ${ }^{\star 3}$

$\approx$ This paper synthesises research from three separate studies, analysing how different representations of a mathematical concept may affect young children's engagement with mathematical activities. Children between five and seven years old engaged in counting objects, identifying triangles and completing repeating patterns. The implementation of three counting principles were investigated: the one-to-one principle, the stable-order principle and the cardinal principal. Children's reasoning when identifying triangles was analysed in terms of visual, critical and non-critical attribute reasoning. With regard to repeating patterns, we analyse children's references to the minimal unit of repeat of the pattern. Results are discussed in terms of three functions of multiple external representations: to complement, to constrain and to construct.

Keywords: counting, multiple representations, repeating patterns, triangles, young children 


\section{Vključevanje otrok v matematične aktivnosti, ki vključujejo različne reprezentacije: trikotniki, vzorci in štetje}

Dina Tirosh, Pessia Tsamir, Ruthi Barkai in Esther Levenson

$\propto$ Prispevek povzema ugotovitve treh ločenih raziskav, v katerih smo preučevali, kako različne reprezentacije matematičnih pojmov vplivajo na otrokovo odzivanje v matematičnih aktivnostih. Otroci, stari od pet do sedem let, so šteli objekte, prepoznavali trikotnike in nadaljevali vzorce. Pri štetju smo ugotavljali otrokovo poznavanje treh ključnih načel štetja: prirejanje drug drugemu, konstantnost vrstnega reda pri štetju in načelo kardinalnosti. Pri preučevanju otrokovega prepoznavanja trikotnikov smo analizirali ugotovitve otrok glede na to, kako so jih identificirali: le na osnovi videza ali upoštevajoč ključne karakteristike trikotnika. Pri preučevanju vzorcev smo se osredinili na otrokovo prepoznavanje osnovne enote vzorca, ki predstavlja objekt ponavljanja. Rezultati so predstavljeni glede na tri načine uporabe zunanje reprezentacije, ki so dopolnitev, interpretacija in konstrukcija.

Ključne besede: štetje, multiple reprezentacije, ponavljajoči se vzorci, trikotniki, predšolski otroci 


\section{Introduction}

Young children begin to learn mathematics by examining their environment. How many cookies has mom placed on their plate? What shapes are the cookies? Does the plate have some kind of pattern around its edge? From these interactions, children begin to form concept images. According to Vinner and Hershkowitz (1980), visual representations, impressions and experiences make up the initial concept image, while formal mathematical definitions are usually added at a later stage. The aim of the present study is to explore how different representations of a concept may affect children's engagement with mathematical activities.

Many educators support learning mathematics through multiple representations. Beginning with Dienes (1960), it has been suggested that multiple representations offer embodiments of abstract entities, which in turn help students develop rich understanding and connections to new concepts. External representations include concrete manipulatives, visual images and symbols. The introduction of touch-screen tablets has added representations that combine the visual and the manipulative; specifically, the need to take into consideration the coordination of eye and hand movements (Sinclair \& de Freitas, 2014). While it is true that the hand may gesture without the eye looking at it, with touch-screen technology, gestures involve the eyes. At times, the hand is subordinate to the eyes, as when a child holds up his fingers and the eyes count the fingers. At other times, neither the hand nor the eye is subordinate. Sinclair and de Freitas (2014) describe a child who sees "seven-ness", which the simultaneous touch on the screen has made possible. Add to this scenario sound, such as one click each time one dot appears on the screen, and there is an interplay between three senses: seeing, hearing, and touch.

Ainsworth (2006) suggested three functions of multiple external representations: to complement, to constrain and to construct. Different representations complement each other when they differ in the processes they each support, or in the information they contain. Different combinations of representations can support learning when one representation constrains (i.e., restricts the scope of) interpretation of a second representation. Finally, a deeper understanding is constructed when students integrate information from multiple representations that would be difficult to gain with only one representation.

For the past several years, we have been investigating young children's (aged 4-7 years) engagement with various mathematical activities within three major domains: number concepts, geometry and repeating patterns (e.g., Tsamir, Tirosh, \& Levenson, 2008; Tsamir, Tirosh, Levenson, Barkai, \& Tabach, 2017). Mathematical activities within these domains often involve different 
representations of the same mathematical concept. Representations may be tangible (such as representing the abstract concept of six with six coloured beads) or visual (such as a drawing of a triangle). Even when all representations are tangible, they may still vary (such as having six beads in a row or six beads bunched up together). The present paper integrates these different studies and focuses on three activities - counting, identifying triangles and extending repeating patterns - when different representations are encountered by children.

\section{Related background}

Because the paper deals with three different mathematical subjects, this section offers a brief review of some definitions, competencies and representations related to each subject.

\section{Counting objects}

Object counting refers to counting objects for the purpose of saying how many. Gelman and Gallistel (1978) outlined five principles of counting objects. The three "how-to-count" principles include the one-to-one principle, the stable-order principle and the cardinal principle. The two "what-to-count" principles include the abstraction principle and the order-irrelevance principle. Implementing the stable-order principle is based on being able to count verbally. This is more than a rote skill; it includes being able to say the number words in the proper order and knowing the principles and patterns in the number system as coded in one's natural language (Baroody, 1987). Typically, most sequences up to thirty produced by children begin with an accurate portion of the number-word sequence, followed by a stable but incorrect portion between two to six words, and then a non-stable incorrect sequence of number words (Fuson, 1991). The relationship to language may be seen in the difficulties of English-speaking (and Hebrew-speaking) children when learning the number words from 11 to 20, and going from 29 to 30 (Han \& Ginsburg, 2001). Competence in object counting may be related to the number of objects to be counted, as well as how the objects are set up (Gelman \& Gallistel, 1978). In addition, children may show knowledge of one principle while violating another principle; for example, erring with regard to the one-to-one correspondence principle, but showing understanding of cardinality (Geary et al., 1992).

During the early years, number concepts are often represented by manipulatives. "Manipulative materials are objects designed to represent explicitly and concretely mathematical ideas that are abstract. They have both visual and 
tactile appeal and can be manipulated by learners through hands-on experiences" (Moyer, 2001, p. 176). In other words, representations need to be manipulated and actively operated on, in order to develop mental images that can be used later in the mental manipulations of abstract concepts. An example of this may be seen in one pre-K-2 programme aimed at developing children's number sense (Griffin, 2004). One of the main principles of this programme was to expose children to the main ways number is represented and talked about in society. Thus, children encounter number represented by dot patterns on a die, the distance a pawn moves on a game board, sets of buckets illustrated on playing cards, and written numerals. Children act on these representations (e.g., counting the dots, moving their pawn) and with repeated play become capable of mentally doing some arithmetic operations, such as successive addition. According to Moyer (2001), manipulatives (and, by extension, perhaps other representations) become meaningful in the process of using them within shared environments. "The physicality of concrete manipulatives does not carry the meaning of the mathematical ideas behind them. Students must reflect on their actions with the manipulatives to build meaning" (p. 177). In the present study, we focus on counting physical objects, where number is represented as the cardinality of a set of objects and the set representation differs from task to task.

\section{Identifying two-dimensional figures}

The acquisition of geometrical concepts includes both visual and attributional reasoning. According to the van Hiele theory (e.g., van Hiele \& van Hiele, 1958), at the most basic level, children use visual reasoning, taking in the whole shape without considering that the shape is made up of separate components. Students at this level can name shapes and distinguish between similar looking shapes. At the second level, students begin to notice that different shapes have different attributes, but the attributes are not perceived as being related. At the third van Hiele level, relationships between attributes are perceived and definitions are meaningful. If the student points out that a figure is a quadrilateral because it has four sides and, therefore, it also has four angles and vertices, then that child may be operating at the third van Hiele level.

Attributes may be critical or not-critical (Hershkowitz, 1989). In mathematics, critical attributes stem from the concept definition. For example, the critical attributes of a quadrilateral include (a) closed figure, (b) four sides, (c) four vertices, (d) four angles. Non-critical attributes include the overall size of the figure (large or small) and orientation (horizontal base). As educators, we aim for students to use only critical attributes as the deciding factor in 
identifying examples and forming geometrical concepts. In her study of young children's understanding of shapes, Hannibal (1999) found that many children reverted to the use of non-critical attributes when trying to differentiate between examples and non-examples among similar shapes. Burger and Shaughnessy (1986) claimed that an individual's reference to non-critical attributes has an element of visual reasoning. Thus, they further claimed that a child using this reasoning may either be at van Hiele level one or at van Hiele level two, as $\mathrm{s} / \mathrm{he}$ is pointing to a specific attribute, and not judging the figure as a whole.

In the realm of geometry, representations often take the form of figures. In his study of figural concepts, Fischbein (1993) referred to an image as a sensorial representation. The concept (e.g., triangle) "is the general idea of a class of substances having in common a number of properties... The image... is the sensorial representation of the respective object (including color, magnitude, etc.)" (p. 139). Thus, when examining the properties of a triangle, for example, the triangle drawn on a piece of paper represents an infinite class of objects; it is a general representation. Mental operations may be performed on these figures, such as modifying, displacing, cutting, etc. The complexity of working with figural representations is exemplified in one experiment where children in grades 2-6 were asked to compare the point of intersection between two lines with the point of intersection between four lines. The findings showed that the younger children's replies reflected their view of the figures as concrete representations, whereas the older children had a more abstract-conceptual view. In a related study, Tsamir, Tirosh and Levenson (2008) differentiated between intuitive and non-intuitive non-examples and also found that children related some figures to concrete objects. In the present study, we focus on examples of triangles, that is, different representations of triangles and the reasoning children use when identifying these representations.

\section{Children's repeating patterning competencies}

Repeating patterns are patterns with a cyclical repetition of an identifiable "unit of repeat" (Zazkis \& Liljedhal, 2002). For example, the pattern ABBABBABB... has a minimal unit of repeat of length three. Educators have noted that exploring repeating patterns may promote children's appreciation of underlying structures (e.g., Starkey, Klein, \& Wakeley, 2004). Structure, however, is an abstract concept. For young children, recognising structure comes from observing and engaging with concrete repeating patterns. For example, studies found that children may spontaneously build their own $\mathrm{AB}$ and $\mathrm{ABC}$ patterns with blocks or by painting stripes (Fox, 2005; Seo \& Ginsburg, 2004), calling out the pattern they are making, such as red, blue, red blue, and so on. 
Previous studies have investigated children's engagement with various pattern tasks, such as extension, duplication and completion tasks. Papic et al., (2011) reported that many children succeed at extension and duplication tasks by employing a "matching one item at a time" strategy. This strategy is very successful with simple $\mathrm{AB}$ patterns, but less so with more complex patterns. For example, when asked to replicate a 12-block tower made up of three repetitions of a red-blue-blue-black unit, one child claimed that the tower was not a pattern. When asked why it was not a pattern, the child replied "because it can't have two of the same color next to each other... You have to have different colours like red, blue, black. Then it's a pattern" (p. 253).

Another type of pattern task is when a child is requested to construct or draw the same kind of pattern as a given pattern, but with different materials (Rittle-Johnson et al., 2013). For example, if an AABB pattern is constructed from red and blue cubes, then the child is given triangles and circles to construct a similar pattern. In other words, the child is requested to translate between different representations of the same pattern. Such a task is considered to be more advanced than being able to duplicate, extend or fix a pattern (Sarama \& Clements, 2009). In the present study, we examine children's engagement with patterns represented by physical materials and patterns represented pictorially on a tablet application.

In this paper we review studies of young children engaging with concrete, figural and tablet representations of three mathematical concepts: counting objects, identifying triangles and completing repeating patterns. According to Ainsworth (2006), there are three functions of multiple external representations: to complement, to constrain and to construct. The aim of this study is to explore these three functions within different mathematical contexts.

\section{The current study}

In this paper, we integrate results from three different investigations, each focusing on a different mathematical context with children aged 4-7 years. As such, the following sections present the methodology and results separately for each mathematical context. The discussion at the end synthesises results.

\section{Counting objects}

\section{Problem definition and research questions}

Learning to count objects is complex and may require different skills depending on the objects to be counted and their physical placement. Previous 
studies have focused on pictorial number representations, such as counting dots on dice (Griffin, 2004), or on children's counting strategies when asked to count a set of concrete objects (Baroody, 1987). The present study focuses on two physical attributes of the objects to be counted: their colour and the way they are set up. Specifically, we asked: Is there a difference between children's ability to count objects in a row as opposed to objects in a circle? Is there a difference between children's ability to count identical objects as opposed to objects that are not identical?

\section{Methodology and data procedure}

The participants were 39 children between the ages of 4 and 5 , ages when children are still developing their counting skills. They were gathered from four preschool classes in the same middle-low socioeconomic neighbourhood. All of the children were interviewed by the researcher in a quiet corner of the classroom.

The first task involved placing eight different objects in a row on the table in front of the child and asking: How many objects are here? The objects were a pencil, pen, pencil, eraser, sharpener, pencil, crayon and eraser. These objects were each distinct, which we thought would encourage one-to-one correspondence, yet they belong together in a set as they are generally found in a pencil case. After the children verbally counted the objects (sometimes correctly and sometimes not) they were asked: So how many are there? Three counting skills were assessed: using the correct counting words in the correct order, using one-to-one correspondence, and the cardinality principle. The cardinality principle was assessed based on the children's responses to the last question. In other words, whether they repeated the last number word they had said, or whether they started counting the objects again from the beginning. Out of the original 39 children, 20 demonstrated knowledge of all three skills, and it was these 20 children who engaged in the rest of the tasks. It was thought that if the children did not show evidence of these basic counting skills when nonidentical objects were placed in a row, having them cope with situations that are more complex might place undue stress on them and would not provide us with additional meaningful data.

The second task involved placing seven identical bottle caps in a circle and asking: How many bottle caps are here? The aim was to see how children would cope with counting items in a circle when there is no obvious place to begin or end. After the children had answered, the caps were removed from the table and a set of nine caps were placed on the table: eight identical bottle caps and one additional cap of a different colour. The caps were arranged in a circle with the different coloured cap placed on the bottom of the circle, in relation to 
where the child was sitting. Here, we were interested in seeing whether the children would use the different cap as an anchor or a sign of where to begin and end their counting. Again, the child was asked: How many bottle caps are here? After the child answered, those caps were removed from the table and a third set of caps was placed on the table in a circle: seven caps, each of which was different from the others. Here we were interested to see whether having all different items would have an effect on children's counting strategy; in particular, whether it would be different from the second task, when all of the items were identical. Although the children were not directly told that the objects should not be moved, it seemed from their actions that this was implicitly understood, as no child moved the caps.

\section{Results}

From Table 1 we see that it was easier for children to manage counting skills when items were placed in a row, rather than in a circle. When counting in a row, all of the children began to count from one end, and continued to count in order until they reached the end. Interestingly, when the caps were presented in a circle, two of the children simply said "I don't know", without even attempting to count the items. This points to children who may not have experience counting objects that are not arranged in a set order. On the other hand, once the caps were placed in a circle, it did not seem to make any difference whether they were identical or not.

Table 1

Frequencies (\%) of correct answers

\begin{tabular}{ccccc}
\hline & Placed in a row & \multicolumn{3}{c}{ Placed in a circle } \\
\hline $\begin{array}{c}\text { Task 1 } \\
8 \text { items in a pencil } \\
\text { case }\end{array}$ & $\begin{array}{c}\text { Task 2 } \\
7 \text { identical caps }\end{array}$ & $\begin{array}{c}\text { Task 3 } \\
9 \text { caps: } 1 \text { different } \\
\text { and } 8 \text { identical }\end{array}$ & $\begin{array}{c}\text { Task } 4 \\
\text { caps of different } \\
\text { colours }\end{array}$ \\
\hline Frequency & $20(100)$ & $11(55)$ & $8(40)$ & $10(50)$ \\
\hline
\end{tabular}

In order to examine more closely how the different representations led to different counting strategies, we present a few examples of the children's counting strategies, beginning with the children who succeeded in all four tasks, proceeding with the children who completed the first two tasks correctly but not the last two, and ending with the children who incorrectly counted the caps in Task 2, but then had different results in the last two tasks.

Natalie and Nitzan (these and all other names are pseudonyms) correctly counted the objects in all four tasks. For Task 3, Natalie began counting with 
the different coloured cap; that is, the different coloured cap was "one" and she ended when she counted the cap preceding the different coloured cap. Nitzan used a different strategy for Task 3 . She began counting "one" with the cap that came after (in a clockwise rotation) the different coloured cap, and ended when she counted the different coloured cap.

Michael correctly counted the caps in Tasks 1 and 2, but then got confused in Tasks 3 and 4. Using the same strategy as Natalie for Task 3 , he counted "one" as he touched the different coloured cap. However, he also ended with the different coloured cap, essentially counting it twice. He made the same mistake in Task 4, when he again ended with the cap he had begun counting with, thus counting it twice.

Finally, we turn to Lior and Liele. Both counted one extra bottle cap in Task 2, claiming that there were eight caps in the circle. In Task 3, Lior began counting with the different coloured cap and counted correctly. For the last task, he also counted correctly. Liele, on the other hand, did not start counting from the different coloured cap in Task 3, and ended up counting one of the caps twice, claiming that there were 10 caps. He made the same mistake again for Task 4, incorrectly claiming there were 8 caps.

To summarise, four concrete representations of a set were presented to the children. It was thought that the circular representation might cause them to keep on counting while they went around in circles, counting until they got tired or confused. However, none of the children over-counted by more than two. In other words, although we cannot say for sure what strategy the children used to keep track of their counting, it could be that the circular identical caps representation caused children to focus or concentrate more on keeping track of their actions, knowing that there had to be a beginning and an end. In addition, most of the children attempted to use the different coloured cap in the third representation, again indicating an understanding that they needed to control their actions. To conclude, once the children demonstrated competence with the one-to-one principle, the stable-order principle and the cardinal principle, different representations of sets of objects may be seen to encourage control and reflection.

\section{Identifying triangles}

\section{Problem definition and research questions}

Triangles are visual representations of formal mathematical objects. According to van Hiele, (e.g., van Hiele \& van Hiele, 1958), children can be assisted to move from one level of reasoning to another. Thus, it is important to know which examples may promote children's attribute reasoning and which 
examples may encourage them to focus on critical rather than non-critical reasoning (Hershkowitz, 1989). In the present study we asked: Are some representations more easily identified as triangles than others? Do children use different levels of reasoning (i.e., according to van Hiele) when identifying different triangle representations?

\section{Methodology and data procedure}

Twenty-five children (called $\mathrm{C}_{1}$ through $\mathrm{C}_{25}$ ) between the ages of 5-6 years participated in this study. The children were attending municipal kindergartens, in the same middle-low socioeconomic neighbourhood, the year before entering the first grade. According to the Israel National Mathematics Preschool Curriculum, at this age, children learn to identify various polygons, along with recognising critical attributes (e.g., the number of sides, vertices, etc.). All of the children were interviewed by the researcher in a quiet corner of the classroom.

The task involved eight different figures - three triangles and five nontriangles - each of which was printed on a separate card. The figures and the order in which they were given was the same for each child. After presenting each card in the same order to each child, two interview questions were asked: Is this a triangle? Why? The first question ascertained whether the child correctly identified the figure as a triangle or a non-triangle, while the second question allowed us to study the child's reasoning about the identification of a figure and whether different representations gave rise to different reasoning. As this study focuses on representations of a concept, we focus on the figures that represent triangles (see Figure 1; for the full set of figures see Tirosh, Tsamir, Levenson, Tabach, \& Barkai, 2013).
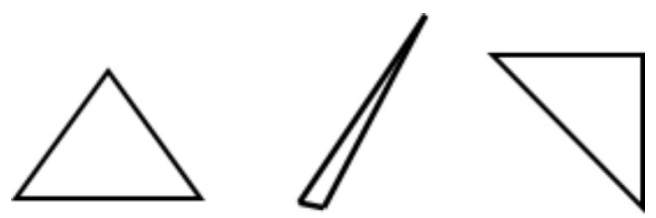

Figure 1. Equilateral, acute and right triangles.

Two sets of data were analysed, corresponding to the two interview questions. The first set of data consisted of the children's responses to the question of identification, i.e., whether the child correctly identified the figure as a triangle. The second set of data resulted from the children's reasoning about the identification of a figure (see Table 2). 
Using the van Hiele levels of geometrical thought, the children's reasoning was first sorted into visual reasoning and reasoning based on the figure's attributes. Within the category of visual reasoning were responses based on appearance alone, where the figure was perceived as a whole. An example of such reasoning was one child, $\mathrm{C}_{23}$, who claimed that the equilateral triangle was a triangle because "You see it". Another example was $\mathrm{C}_{5}$, who said that the acute triangle is not a triangle "because it's a thorn". The second level of van Hiele thought is reasoning based on attributes. As discussed in the background, attributes may be further divided into critical and non-critical attributes. As in our previous study of nontriangles (Tsamir, Tirosh, \& Levenson, 2008), we consider that a triangle has four critical attributes: (a) closed figure, (b) three, (c) vertices, (d) straight sides. Noncritical attributes are "usually attributes of a prototypical example only" (Hershkowitz, 1989, p. 69). These attributes might refer to the length of the sides, the measurement of the angles or the orientation of the figure.

Table 2

Coding reasons after identifying a figure

\begin{tabular}{ll}
\hline Category & Reasons \\
\hline $\begin{array}{l}\text { Purely visual reference to the } \\
\text { whole figure }\end{array}$ & $\begin{array}{l}\text { "It looks (doesn't look) like a triangle." } \\
\text { "You see (don't see) the shape." } \\
\text { "It's not a triangle. It's a thorn (referring to the acute triangle)." }\end{array}$ \\
\hline $\begin{array}{l}\text { Reference to non-critical } \\
\text { attributes }\end{array}$ & $\begin{array}{l}\text { "Because this (points to a particular side) is too small (short, big, } \\
\text { long)." } \\
\text { "It's (referring to the figure) too thin (fat, long, sharp)." }\end{array}$ \\
\hline Reference to critical attributes & "It has three (four, five, many, no) sides (lines, points, corners)." \\
\hline
\end{tabular}

Although reasoning based on non-critical attributes should fall under the second van-Hiele level of attribute reasoning, it might also be considered partly visual. Comparing a figure to prototypical examples is what Hershkowitz (1990) called prototypical judgment. This may be partly visual judgment, as the "prototype's irrelevant attributes usually have strong visual characteristics" (p. 83). Thus, we suggest that reasoning based on non-critical attributes may serve as a bridge between the first and second van Hiele levels of thought. Our second category was reasoning based on non-critical attributes. For example, when discussing the acute triangle, $\mathrm{C}_{22}$ claimed that it was not a triangle because "it's too long". The third category was reasoning based on critical attributes. Some of the children correctly used the critical attributes by counting sides or vertices, for example. Others referred to critical attributes but applied them incorrectly. For example, C15, looking at the acute triangle, said "It's not a triangle because it doesn't have three sides, only two". Table 2 lists common examples of the 
children's reasoning and their categorisation. The children who gave more than one reason in two different categories were given more than one code, in accordance with the appropriate categories.

\section{Results}

Regarding identifications of the triangles, all of the children correctly identified the equilateral triangle, $68 \%$ correctly identified the right triangle, and $16 \%$ correctly identified the acute triangle. Table 3 reports on the frequencies of the types of reasoning associated with each triangle representation. Note that some of the children gave more than one reason, and thus the total for each row is greater than 25; for example, there were 29 reasons given for why the equilateral triangle is a triangle. Viewed globally, visual reasoning was the most frequent type of reasoning. Specifically, for the equilateral triangle, the children most often used visual reasoning or reasoning based on critical attributes. For the acute triangle, they used either visual or non-critical attribute reasoning, whereas for the right triangle, they used mostly visual reasoning, and to a lesser extent, reasoning based on critical attributes.

Table 3

Frequency of reasoning associated with triangle identification

\begin{tabular}{lccccccccc}
\hline & \multicolumn{8}{c}{ Types of reasoning } \\
\cline { 2 - 9 } Triangles & \multicolumn{3}{c}{ Visual } & \multicolumn{1}{c}{ Non-critical attributes } & \multicolumn{2}{c}{ Critical attributes } \\
\cline { 2 - 10 } & correct & incorrect & total & correct & incorrect & total & correct & incorrect & total \\
\hline Equi-lateral & 13 & - & 13 & 4 & - & 4 & 12 & - & 12 \\
Acute & - & 10 & 10 & 1 & 9 & 10 & 3 & 3 & 6 \\
Right & 8 & 4 & 12 & 3 & 4 & 7 & 9 & - & 9 \\
\hline
\end{tabular}

We now examine some trends in the children's reasoning more closely. Out of the 25 children interviewed, 10 children (40\%) gave the same type of reasoning for each triangle. Four children consistently used visual reasoning, two used non-critical attributes, and four consistently used critical attribute reasoning. The rest of the children (6o\%) seemed to use different reasoning for different representations. $\mathrm{C}_{3}$, for example, explained that the equilateral triangle is a triangle because "they made it a triangle". "Making" a triangle is reminiscent of Fischbein's (1993) example of children concretising figural representations, and may be categorised as visual reasoning. $\mathrm{C}_{3}$ explained that the acute triangle was not a triangle because "it's thin" (a non-critical attribute), and claimed that the right triangle was a triangle because "it has a line, a line, a line" (indicating the critical 
attribute of having three sides, which she calls lines). In other words, $\mathrm{C}_{3}$ went from visual reasoning, to reasoning based on a non-critical attribute, to reasoning based on a critical attribute. C12's reasoning went in the opposite direction. He explained that the equilateral triangle was a triangle because "a triangle has three corners and this has three corners". This refers to the critical attribute of having three vertices or angles. He claimed that the acute triangle was not a triangle because "it's long" (a non-critical attribute), and used visual reasoning when he said that the right triangle is a triangle because "it has the exact shape of a triangle".

To summarise, three visual representations of triangles were presented to the children. In accordance with previous studies (e.g., Hershkowitz, 1989), only the prototypical triangle was recognised as a triangle by all of the children. Regarding reasoning, it seemed that most of the children varied their reasoning with the representation. From the above examples, we also see that the children seem to be operating at both the first and second levels of van Hiele reasoning. While other studies suggested that the van Hiele levels may not be discrete and that a child may display different levels of thinking for different contexts or different tasks (Burger \& Shaughnessy, 1986), the present study showed that children may display different levels of reasoning based on different representations.

\section{Repeating patterns}

\section{Problem definition and research questions}

Repeating patterns may have various structures, such as $\mathrm{AB}, \mathrm{ABB}, \mathrm{ABC}$ and ABA. They may be represented visually with pictures, concretely with physical items, or a combination of visual and manipulative on tablets. In the present study we asked the following questions: Are there pattern structures that children complete more easily than others? In addition, taking into consideration the rather new form of representation on tablets, we ask: Are patterns represented concretely more easily completed than patterns represented on a tablet?

\section{Methodology and data procedure}

In this section, we report on one child - Jubilee, aged seven - who engaged with repeating pattern activities using concrete materials, as well as a tablet application (app), under the guidance of her uncle, Boris. Boris was a student studying for a postgraduate degree in mathematics education. The activity was conducted under the guidance of the researcher, but without the researcher present.

The app had the following attributes: (1) each screen presents two patterns, not necessarily with the same pattern structure, (2) the first unit of repeat in each pattern is highlighted, (3) patterns are presented with elements missing 
in different places, (4) there is a bank of elements on the bottom of the screen that the child chooses from, (5) the child must drag an element from the bank to a blank spot in the pattern, and (6) if a mistake is made, the picture will fall back down to the bank, no hint is given, and the child can try again. If the child is correct, the app keeps the picture in place. When the full pattern is completed, there is a sound of handclapping. In other words, from interpreting the context, without adult intervention, the child can know whether s/he was correct.

At first, Jubilee played with the app freely, becoming familiar with its aim and how it responds to her gestures. Boris then used the concrete materials to explain repeating patterns, showing how they are constructed from units that repeat themselves. He then engaged Jubilee with completion tasks using the concrete materials. Finally, he switched back to the app. The interaction between Boris, Jubilee and the tablet app was video-recorded and transcribed. Qualitative analysis focused on verbal utterances, and, due to the nature of tablet representations, included an analysis of hand gestures.

\section{Results}

The first two patterns on the screen presented to Jubilee were of the form A B _-_- (see Figure 2a). Jubilee explained before acting,

"You take a chicken because they show you these two here (pointing to the highlighted chicken and cow in the beginning) and here there is a cow so then you need to put this (pointing to the chicken) and they show us that you need these two (uses two fingers to point to the two elements highlighted, one finger on the chicken and one finger on the cow)." (See Figure $2 b$.)

The use of two fingers of one hand to touch the elements of the unit hints at Jubilee's recognition that these two elements are one unit. Jubilee then drags the chicken into place and subsequently drags the cow into place, saying, "And now again it repeats itself". The verbal utterance "it" also indicates that Jubilee sees the chicken and cow as one unit: "it". Jubilee correctly completes the second $\mathrm{AB}$ pattern, as well as another two $\mathrm{AB}$ patterns on a different screen.
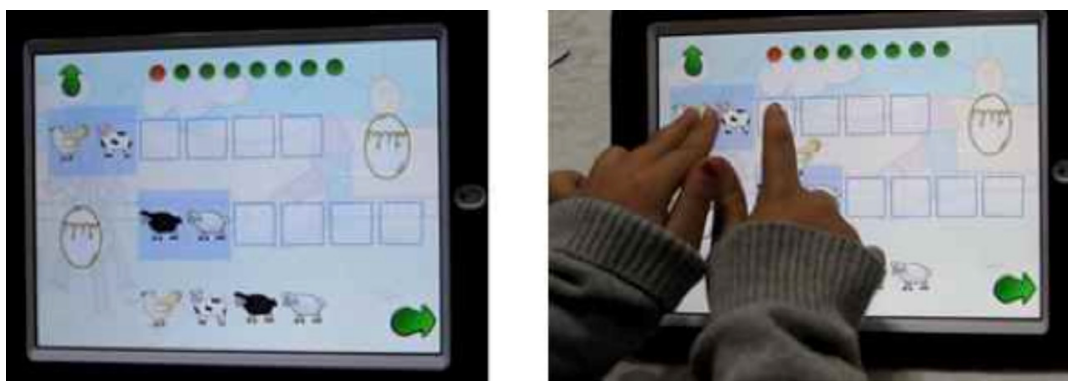

Figures $2 a$ and $2 b$. Jubilee recognising the unit of repeat in an $\mathrm{AB}$ pattern. 
The next screen shows: A B C , and underneath that $\mathrm{A} \mathrm{B} \mathrm{A}$ (see Figure 3a; the eggs at the end of the first and second patterns are not part of the patterns, but merely decorations). Starting with the upper pattern, Jubilee correctly places the correct cat and explains, "Because this is a cat and this and this (pointing to the duck and pig) and this is the end of it" (Jubilee makes an up and down hand motion after the highlighted unit) (see Figure $3 \mathrm{~b}$ ). Jubilee's up and down gesture signifies that the unit ends there. Jubilee then correctly completes the first pattern.
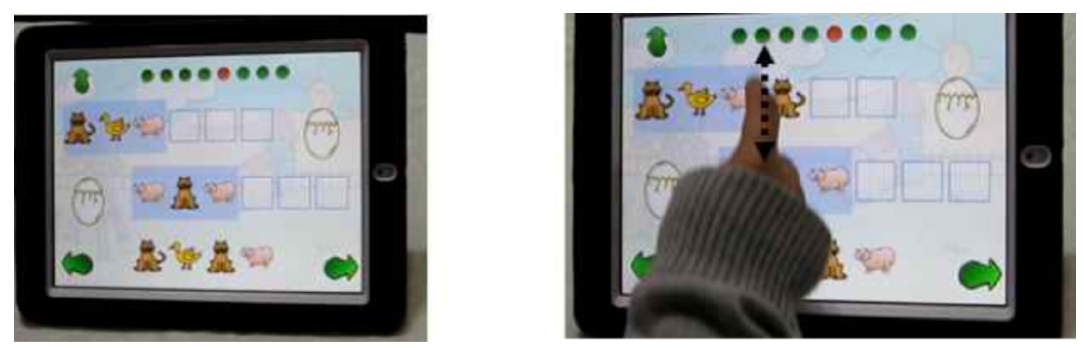

Figures $3 a$ and $3 b$. Jubilee recognising the $\mathrm{ABC}$ unit of repeat.

As Jubilee begins to work on the second pattern, Boris asks her to explain before dragging any of the pictures. (Note that the bank in Figure $2 \mathrm{a}$ has two cats - one with a tail and one without a tail).

Jubilee: Because here there is a pig (points to the first pig in the highlighted unit) and here is a cat (points to the cat-without-a-tail after the pig) so here you need again a pig (points to the second pig in the unit) and then again a cat.

Jubilee does not indicate that she is aware of the unit of repeat. She points out the first pig, then the cat, and, as if that is the unit, she says "so here you need again a pig". The "again" seems to indicate that this second pig begins the next unit. Jubilee drags the cat-without-a-tail into the first empty spot, but it drops back down. She then tries the cat-with-a-tail, but that also drops back down. She then pauses (five seconds) and says, "I don't know". She then drags the duck, which also falls back down. Finally, she drags the pig into place, and quickly completes the rest of the pattern with a cat and a pig. The last two patterns, an $\mathrm{ABB}$ and an $\mathrm{ABC}$ pattern, are completed without error.

After a short break, Boris closes the tablet and takes out coins of different denominations. Using the coins, he proceeds to construct an $\mathrm{AB}$ pattern with six repeats of the basic minimal unit, taking the opportunity to explain out loud to Jubilee that the coin pattern is made up of units that repeat, and that in this case the unit has two elements. He then clears away the AB pattern and 
constructs an $\mathrm{ABC}$ pattern, repeating his explanation and requesting that $\mathrm{Ju}-$ bilee continue the pattern, which she does correctly. After this demonstration, he continues by constructing an AAB pattern and asks Jubilee to tell him how many coins make up the unit of repeat and how many times the unit repeats itself. Jubilee answers correctly each time. Boris then requests Jubilee to close her eyes while he removes two elements from the pattern. Opening her eyes, Jubilee is requested to fill in the missing elements, which she does correctly. This game is repeated, with Boris finally constructing an ABA pattern. Jubilee correctly recognises the three elements of the unit repeat (see Figure 4), correctly acknowledges how many times the unit repeats itself, and correctly fills in the missing element, after having closed her eyes when Boris removed it (see Figure 5).

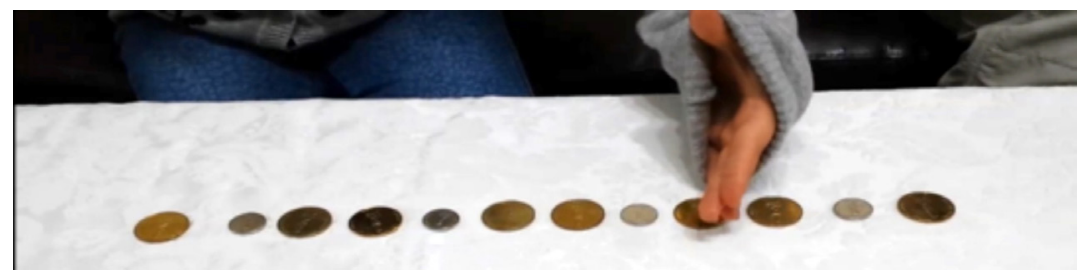

Figure 4. Jubilee shows where the unit of repeat ends and a new one begins.

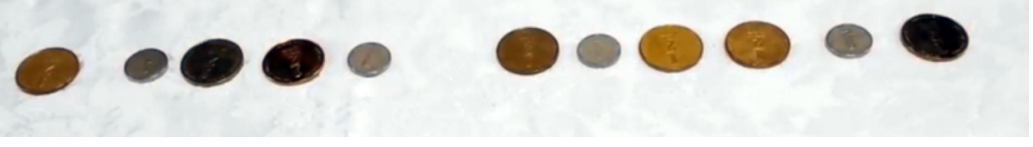

Figure 5. Fill in the missing element.

Once again there is a break, and Boris reintroduces the same tablet app as before. This time, however, Boris asks Jubilee to identify the unit of repeat for each pattern before filling in the missing elements. He also asks Jubilee to say how many times the unit repeats itself in each pattern. Jubilee correctly engages with two AB patterns, as well as an ABC pattern (see the bottom pattern of Figure 5). She correctly identifies the unit of repeat by saying that it contains a bathing suit, a sun umbrella and a ball, and correctly tells Boris that there are two units in the pattern. She then encounters the following pattern: A B A $\_--$.

Jubilee mistakenly drags the wrong beach ball (see Figure 6; the snaillike figures at the end of the first pattern and the beginning of the second pattern are merely decorations and not part of the pattern), which drops down, and the following interaction occurs: 


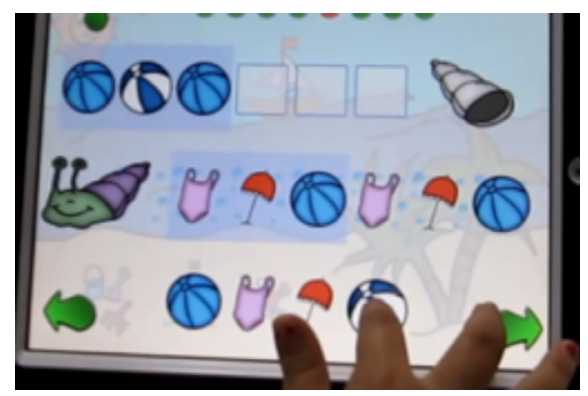

Figure 6. Jubilee drags the incorrect ball into place.

Boris: Tell me first, what is the unit of repeat? Can you identify the unit of repeat?

Jubilee ignores his question and correctly completes the pattern.

Jubilee: But Boris, it can't be. There are two of these (pointing to the two dark blue balls).

Boris: Try to identify the unit that repeats itself here.

Jubilee is quiet while she uses her finger to point to the different elements.

Boris: Try to identify the elements of the unit. What is the unit made up of? Jubilee: Oh, I understand. If here there was three (circling the highlighted unit), if this begins here (pointing to the first ball), then it also has to be here (pointing to the fourth ball, essentially the first ball of the second unit of repeat).

In this last statement, Jubilee does not answer Boris. Instead, she seems to revert to a "matching one item at a time" strategy (Papic, et al., 2011) in order to resolve the problem. After this encounter, Jubilee correctly completes the rest of the patterns.

Summarising the encounter with Jubilee and Boris, we first note the complexity of the representations involved in the repeating patterns. First, there are different structures, all representing repeating patterns. Then, the same pattern structure may be represented by different elements (e.g., beach objects, animals). Finally, there is the difference between concrete representations and tablet representations. Regarding structures, Jubilee was able to complete all $\mathrm{AB}, \mathrm{ABB}$ and $\mathrm{ABC}$ patterns, regardless of whether they were presented on the tablet or with concrete objects. After encountering the language of patterns, she was able to identify the unit of repeat in $\mathrm{AB}$ and $\mathrm{ABC}$ patterns, both when engaging with concrete coins and when engaging with the tablet.

The difference between the coin and tablet representations was only noticeable when engaging with ABA patterns. This is curious, because the tablet representation actually highlighted the unit of repeat, and Jubilee's gestures and 
utterances hinted at an understanding of what the highlighting represented. Yet, despite the highlight, it could be that Jubilee thought that the ABA pattern was the beginning of an $A B A B A B A B$ pattern. In addition, on the tablet, only one unit of repeat was represented, while with the manipulatives, four units of repeat were placed on the table. It could be that, for identifying structure, it is of greater value for the child to see several repeats of the same structure, rather than merely telling or showing the child that this is the structure.

\section{Discussion}

Although the three studies reported above were set in different contexts, all three focused on young children and the way different representations may affect the way children engage mathematically. The first study employed representation that varied in colour and set-up, the second study focused on intuitive and non-intuitive representations of triangles, and the third study focused on concrete versus tablet pattern representations. The reason for reporting on the three studies together was to gain knowledge in various contexts of what Ainsworth (2006) suggested as the three functions of multiple external representations: to complement, to constrain and to construct.

In the first study (when the children counted objects), the different representations complemented each other by offering different information, such as where to begin and where to end the counting process. When identifying triangles, the information was theoretically the same; however, due to the van Hiele level of most children at this age, they pay more attention to visual information than to abstract geometrical information. When completing repeating patterns, the concrete and tablet representations complemented each other by containing different information. Focusing on the ABA patterns, the concrete representation offered an expanded pattern with several repeats of the minimal unit of repeat, whereby the tablet representation highlighted the unit of repeat, but only showed the one unit.

The constraining function of multiple representations was observed to a lesser extent. The different triangle representations did not seem to restrict the scope of interpretation of different triangles in any way, nor did the different pattern representations. Perhaps when counting objects it might be said that the representation of a set of items in a row constrains the interpretation of a set of items being placed in a circle, in that the row reminds the child that counting, even in a circle, has a beginning and an end. It might also be that the representation of a set by all identical objects except for one of a different colour, might have restricted the following set representation, where all objects were of a different colour. In other words, the first set might have clarified the necessity 
of finding a beginning and an end when enumerating all of the sets, regardless of how they look. However, it did not seem to impact on the children's engagement with the last counting task.

Finally, the third function of using multiple representations is to support the construction of a deeper understanding by integrating information from the different representations. This is perhaps most obvious when identifying triangles, as different representations elicited different types of reasoning. Teachers could build on this information to perhaps order the examples, as well as the non-examples (Tsamir et al., 2008), to support the recognition of critical attributes. Regarding the repeating patterns, it might be that Jubilee was finally able to complete the ABA pattern on the tablet by integrating what she had learned from engaging with both types of representations: the concrete and the tablet representation.

In this paper, we reviewed studies of young children engaging with concrete, figural and tablet representations of mathematical concepts. Unlike other studies (e.g., Griffin, 2004), we did not compare the difference between concrete and figural representations in the same context. Instead, we showed that, even when using the same physical materials, representations can be varied to support children's learning. Indeed, although we compared tablet representations to concrete representation, in the case of the concrete representations of a repeating pattern, the child did not actually manipulate the items, so in fact, in this sense, it was similar to the tablet representation. To conclude, there is still more for us to learn about how various external representations, even similar types of representations, can afford young children different opportunities to engage with mathematical learning.

\section{Acknowledgement}

This research was supported by The Israel Science Foundation (grant No. 1270/14).

\section{References}

Ainsworth, S. (2006). DeFT: A conceptual framework for considering learning with multiple representations. Learning and Instruction, 16(3), 183-198.

Baroody, A. J. (1987). Children's mathematical thinking: A developmental framework for preschool, primary, and special education teachers. New York, NY: Teacher's College Press.

Burger, W., \& Shaughnessy, J. (1986). Characterizing the van Hiele levels of development in geometry. Journal for Research in Mathematics Education, 17(1), 31-48.

Dienes, Z. P. (1969). Building Up Mathematics. London, UK: Hutchison Education.

Fischbein, E. (1993). The theory of figural concepts. Educational Studies in Mathematics, 24(2), 139-162. Fuson, K. C. (1991). Children's early counting: Saying the number-word sequence, counting objects, 
and understanding cardinality. In K. Durkin \& B. Shire (Eds.), Language and mathematical education (pp. 27-39). Milton Keynes, UK: Open University Press.

Geary, D. C., Bow-Thomas, C. C., \& Yao, Y. (1992). Counting knowledge and skill in cognitive addition: A comparison of normal and mathematically disabled children. Journal of Experimental Child Psychology, 54(3), 372-391.

Gelman, R., \& Gallistel, C. (1978). The child's understanding of number. Cambridge, MA: Harvard University Press.

Griffin, S. (2004). Building number sense with Number Worlds: A mathematics program for young children. Early Childhood Research Quarterly, 19(1), 173-180.

Han, Y., \& Ginsburg, H. P. (2001). Chinese and English mathematics language: The relation between linguistic clarity and mathematics performance. Mathematical Thinking and Learning, 3(2-3), 201-220. Hannibal, M. (1999). Young children's developing understanding of geometric shapes. Teaching Children Mathematics, 5(6), 353-357.

Hershkowitz, R. (1989). Visualization in geometry - two sides of the coin. Focus on Learning Problems in Mathematics, 11(1), 61-76.

Moyer, P. S. (2001). Are we having fun yet? How teachers use manipulatives to teach mathematics. Educational Studies in mathematics, 47(2), 175-197.

Rittle-Johnson, B., Fyfe, E. R., McLean, L. E., \& McEldoon, K. L. (2013). Emerging understanding of patterning in 4-year-olds. Journal of Cognition and Development, 14(3), 376-396.

Sarama, J., \& Clements, D. (2009). Early childhood mathematics education research: Learning trajectories for young children. London, UK: Routledge.

Tirosh, D., Tsamir, P., Levenson, E., Tabach, M., \& Barkai, R. (2013). Two children, three tasks, one set of figures: Highlighting different elements of children's geometric knowledge. In B. Ubuz, C. Haser, \& M. A. Mariotti (Eds.), Proceedings of the eighth congress of the European society for research in mathematics education (CERME 8) (pp. 2228-2237). Ankara: Middle East Technical University and ERME.

Tsamir, P., Tirosh, D., \& Levenson, E. (2008). Intuitive nonexamples: The case of triangles. Educational Studies in Mathematics, 69(2), 81-95.

Tsamir, P., Tirosh, D., Levenson, E., Barkai, R., \& Tabach, M. (2017). Repeating patterns in kindergarten: Findings from children's enactments of two activities. Educational Studies in Mathematics, 96(1), 83-99. van Hiele, P. M., \& van Hiele, D. (1958). A method of initiation into geometry. In H. Freudenthal (Ed.), Report on methods of initiation into geometry (pp. 67-80). Groningen: Walters.

Vinner, S., \& Hershkowitz, R. (1980). Concept images and common cognitive paths in the development of some simple geometric concepts. In R. Karplus (Ed.), Proceedings of the $4^{\text {th }}$ PME international conference (pp. 177-184). Berkley, CA.

Zazkis, R., \& Liljedahl, P. (2002). Generalization of patterns: The tension between algebraic thinking and algebraic notation. Educational Studies in Mathematics, 49(3), 379-402. 


\section{Biographical note}

Dina Tirosh, $\mathrm{PhD}$, is a full professor of mathematics education in the Department of Mathematics, Science and Technology Education at Tel Aviv University. Her main areas of research are: intuition and infinity, the theory of intuitive rules in mathematics and science, early childhood education and mathematics teacher education.

Pessia Tsamir, $\mathrm{PhD}$, is a full professor of mathematics education in the Department of Mathematics, Science and Technology Education at Tel Aviv University. Her main areas of research are: intuition and infinity, the theory of intuitive rules in mathematics and science, the role of errors in mathematics learning and teaching, early childhood education and mathematics teacher education.

RUTHI BARKAI, PhD, is a researcher and teacher educator at the School of Education, Tel Aviv University, and a senior lecturer at the Kibutzim College of Education. Her research interests include: developing mathematical thinking among preschool students and their teachers, teachers' training, connections between proving and reasoning; professional development of preservice and practicing mathematics teachers at elementary and high school levels.

Esther LeVenson, $\mathrm{PhD}$, is a researcher and teacher in the Department of Mathematics, Science and Technology Education at Tel Aviv University, and at the Kibbuztim College of Education. Her research interests include: fostering mathematical creativity among students and teachers, developing mathematical thinking among preschool children and their teachers, and the role examples play in eliciting explanations. 